\title{
TP53 mutations in vulval lichen sclerosus adjacent to squamous cell carcinoma of the vulva
}

\author{
KJ Rolfe, ${ }^{*, 1}$ AB MacLean', JC Crow², E Benjamin'3, WMN Reid' and CW Perrett' \\ 'University Department of Obstetrics \& Gynaecology, Royal Free and University College Medical School, Royal Free Campus, Rowland Hill Street, London \\ NW3 2PF, UK; ${ }^{2}$ Histopathology Department, Royal Free and University College Medical School, Royal Free Campus, Rowland Hill Street, London NW3 \\ 2PF, UK; ${ }^{3}$ Department of Histopathology, Royal Free and University College Medical School, Bloomsbury Campus, London WCIE 6HX, UK
}

\begin{abstract}
Non-neoplastic epithelial lesions of the vulva (NNEDV) lichen sclerosus (LS) and squamous hyperplasia (SH) have been implicated in the pathogenesis of squamous cell carcinoma of the vulva (SCC). To date, there have been no recognisable precursor lesions for SCC associated with NNEDV. TP53 is the most frequent genetic change in human cancers and can indicate both aetiology and molecular pathogenesis of tumours. A total of 27 SCC patients underwent immunohistochemistry (IHC) and TP53 mutational analysis using microdissection and direct sequencing. There were 19 patients with areas of adjacent epidermis: 17 had NNEDV (four SCCs had more than one adjacent lesion) and two had normal epidermis. In all, $70.4 \%$ of the SCCs, $40 \%$ LS and $22.2 \%$ SH demonstrated overexpression of p53. In total, $77.8 \%$ of SCCs, $46.7 \%$ of LS and $22.2 \%$ SH demonstrated mutations in TP53, with the majority of lesions having a mutation in codon 136. Eight cases were identified where the same mutation was identified in the SCC and in the adjacent area. These data suggest that TP53 mutations develop in NNEDV and are intrinsic to the clonal evolution that leads to SCC. The type of mutation detected is more likely to occur due to endogenous cellular changes rather than exogenous carcinogen exposure.
\end{abstract}

British Journal of Cancer (2003) 89, 2249-2253. doi:I0.1038/sj.bjc.660l444 www.bjcancer.com

(C) 2003 Cancer Research UK

Keywords: immunohistochemistry; lichen sclerosus; mutation; p53; squamous cell carcinoma of the vulva

Lichen sclerosus (LS) is an inflammatory disease of unknown aetiology and pathogenesis. It is a disorder of the skin, which is most common in the genital area but can occur anywhere on the body. It affects both sexes and all age groups. In a review by Meffert et al (1995) of 5207 patients, the female-to-male incidence was reported as $6: 1$, with genital involvement in $83 \%$ of cases. The majority of sufferers of anogenital LS are either middle-aged or elderly women. The predominant symptom in females is an intractable itch, which is often associated with dysuria, dyspareunia, dryness of the skin, labial stenosis or fusion and, in children, constipation (Laude et al, 1980).

There have been many studies assessing the risk of squamous cell carcinoma of the vulva (SCC) in inflammatory diseases of the vulva. Wallace (1971) reported that 12 of 290 (4\%) patients developed SCC following a history of LS during a 12-year period but further follow-up studies have shown a wide range of risk of progression (Hart et al, 1975; Meffert et al, 1995; Carlson et al, 1998). Others (Rueda et al, 1994; Scurry et al, 1997; Vilmer et al, 2000) have looked at the skin adjacent to SCC which, not

\footnotetext{
*Correspondence: Dr KJ Rolfe, RAFT, Leopold Moller Building, Mount Vernon Hospital, Northwood, Middlesex Ha6 2RN, UK;

E-mail: rolfek@raft.ac.uk

Presented at the British Gynaecological Cancer Society Meeting, London, 2001.

Received 19 December 2002; revised 29 September 2003; accepted 29 September 2003
}

uncommonly, shows epithelial disorders; the most common are LS and squamous hyperplasia ( $\mathrm{SH})$.

The TP53 gene is located on chromosome 17p13.1; it consists of 11 exons with 10 introns. Exon 1 is noncoding, while exons 5-8 are part of the highly evolutionarily conserved domain. Mutations in the TP53 gene are the most frequent genetic changes in human cancers, and the spectrum of mutations can indicate tumour aetiology and molecular pathogenesis (Levine et al, 1991; Greenblatt et al, 1994). In addition, a comparison of the mutation profile between malignant and potential premalignant lesions can give an indication of the clonality and progression of such tumours.

The aim of this study was to assess the presence of TP53 mutations in SCC and the adjacent non-neoplastic epithelial disorders of the vulva (LS and SH; NNEDV) and to compare the results of the mutation analysis with immunohistochemsitry (IHC) results. It was hoped that the data would also provide information on the clonality of SCC and the carcinogenic progression of adjacent lesions.

\section{MATERIALS AND METHODS}

\section{Sample details}

A total of 27 formalin-fixed, paraffin wax-embedded vulvectomy specimens from the files of the Histopathology Departments of the Royal Free and University College Medical School (Royal Free and Gower Street Campuses) were used with a mean age of $71.6 \pm 8.6$ years (range 49-86 years). Nineteen patients also had adjacent 
epidermis available for microdissection; 17 of these had an NNEDV (LS and/or SH) with a total of 24 NNEDV specimens and two had normal epidermis adjacent to the SCC.

\section{Immunohistochemical analysis}

Sections $(4 \mu \mathrm{m})$ were cut for immunohistochemical analysis and histopathological confirmation of diagnosis by two pathologists (EB, JCC).

The IHC procedure has been described previously (Rolfe et al, 2001, 2002). Briefly, sections were dewaxed in xylene and rehydrated through different grades of ethanol up to distilled water. Endogenous peroxidase was blocked by using a $3 \%$ hydrogen peroxide solution. Antigen retrieval was performed by heating the sections in sodium citrate buffer in a microwave $(2 \times 5 \mathrm{~min})$. Nonspecific binding was blocked by preincubation with $10 \%$ normal rabbit serum for $10 \mathrm{~min}$ at room temperature. A primary mouse monoclonal antibody, which recognises both wildtype and mutant p53 (DO-7, Dako, Ely, Cambs, UK) was applied at $1: 100$ dilution for $1 \mathrm{~h}$ at room temperature. All stages were carried out at room temperature with phosphate-buffered saline used for washing between stages. Following incubation with a secondary antibody, a standard streptavidin-biotin-horseradish complex was then used, with 3, $3^{\prime}$-diaminobenzidine tetrahydrochloride as the chromogen to detect the presence of the p53 protein. Slides were counterstained with Mayers' haemalum (Merck, Lutterworth, Leics, UK).

To ensure staining consistency and reproducibility, a number of precautions were taken: (i) All sections from different blocks were stained as a batch on the same day and the process was repeated four times for each protein; and (ii) results were analysed independently by the three observers (EB, JCC and KJR). In all cases, there was $<5 \%$ variation in staining between sections and observers.

p53 staining was classified as the percentage of positive (brown) nuclei in specific epidermal areas or as a percentage of tumour cells with $\leqslant 10 \%$ counted as negative and $>10 \%$ as positive, as described previously (Rolfe et al, 2002).

\section{Microdissection}

Two sections sequential to the IHC stained slides were dewaxed and rehydrated up to sterile, double-distilled water. Sections were then stained with toluidine blue (Sigma-Aldrich, Poole, Dorset, UK) which enabled the various lesions to be easily identified. Lesions were carefully removed without contamination from surrounding tissue (Figure 1A, B) using a sterile technique with a 27-gauge needles (Davies Health Care) and each lesion placed separately into separate sterile Eppendorf microcentrifuge tubes. Lesions were flooded with $200 \mu \mathrm{l}$ of digestion buffer ( $10 \mathrm{~mm}$ Tris$\mathrm{HCl}, \mathrm{pH} 8.5,1 \mathrm{~mm}$ EDTA, $0.5 \%$ Tween $20^{\mathbb{R}}$ ) containing $1 \mathrm{mg} \mathrm{ml}^{-1}$ of proteinase K (Sigma-Aldrich, Poole, Dorset, UK). Samples were incubated at $37^{\circ} \mathrm{C}$ for $20 \mathrm{~h}$ and then heated to $95^{\circ} \mathrm{C}$ for $10 \mathrm{~min}$ to inactivate the proteinase $\mathrm{K}$. The solution was then centrifuged at 3500 revolutions per minute for $10 \mathrm{~min}$ and the supernatant removed, placed in a sterile $1.5 \mathrm{ml}$ Eppendorf tube, and stored at $4{ }^{\circ} \mathrm{C}$.

\section{PCR}

PCR was performed using commercially available primers for exons 5-8 of TP53 (Cruachem, Glasgow, Scotland; Table 1). PCR was performed using $4 \mu \mathrm{l}$ of the DNA extracted from the paraffin sections in a $50 \mu \mathrm{l}$ PCR mix of $1.5 \mathrm{mM} \mathrm{MgCl}_{2}, 14-17$ pmoles of each primer, $200 \mu \mathrm{m}$ deoxynucleoside triphosphates (Pharmacia, Milton Keynes, Bucks, UK), in the PCR buffer $\left(20 \mathrm{~mm}\left(\mathrm{NH}_{4}\right)_{2} \mathrm{SO}_{4}, 75 \mathrm{~mm}\right.$ Tris-HCl, pH $8.8,0.01 \%$ Tween ${ }^{\mathrm{B}}$ ) with $2.5 \mathrm{U}$ Taq enzyme ('Thermus icelandicus'; Advanced Biotechnologies, Epsom, Surrey,
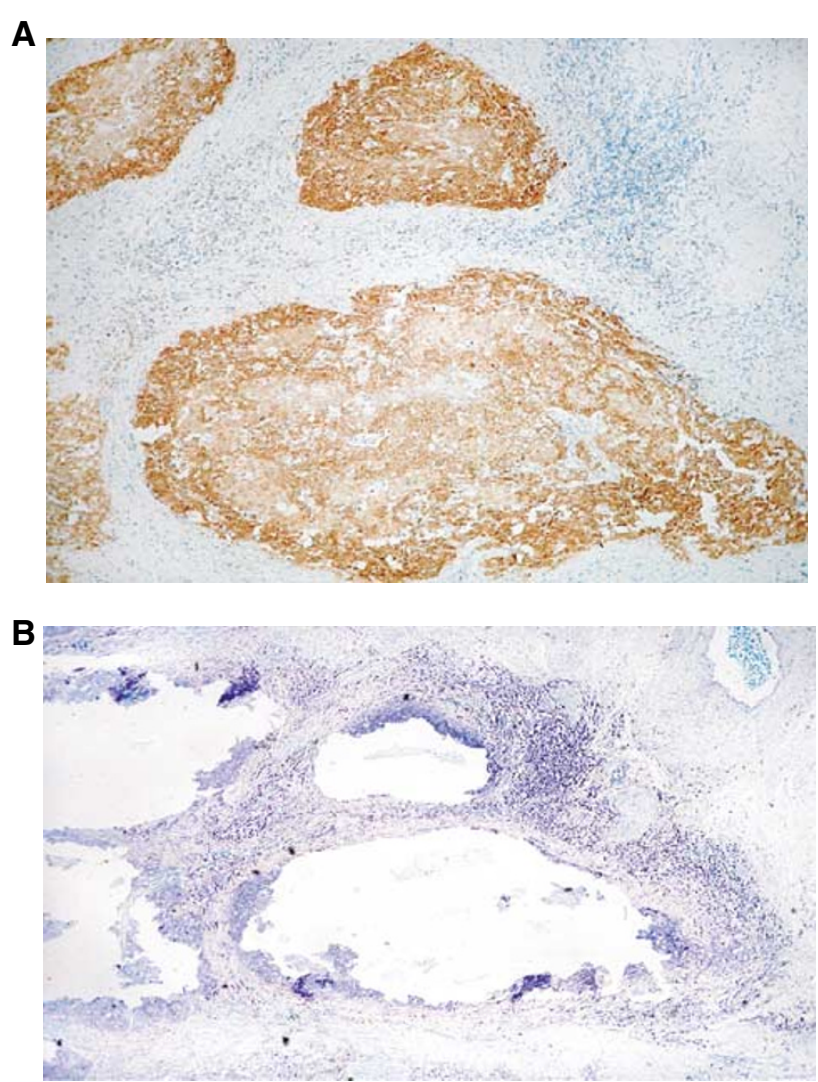

Figure I (A) A slide stained by $\amalg \mathrm{HC}$ showing overexpression of p53 in the SCC. (B) A toluidine blue-stained adjacent slide demonstrating the area that had shown overexpression of p53, removed by microdissection.

Table I Primers used for TP53 PCR amplification

\begin{tabular}{lll}
\hline Exon 5 & Forward & GGAATTCTGTTCACTTGTGCCCTGACTTTCAAC \\
& Reverse & GCAACCAGCCCTGTCGTCTCTCCA \\
Exon 6 & Forward & CCAGGCCTCTGATTCCTCACTGATTG \\
& Reverse & AGGGCCACTGACAACCACCCTTAAC \\
Exon 7 & Forward & CCTGCTTGCCACAGGTCT \\
& Reverse & CCGGAAATGTGATGAGAGGT \\
Exon 8 & Forward & AGGTAGGACCTGATTCCTTACTGCC \\
& Reverse & GGAATTCTGAGGCATAACTGCACCCTTGGTCT \\
\hline
\end{tabular}

UK). PCR was performed over 35 cycles with an annealing temperature for the four exons of $60^{\circ} \mathrm{C}$. PCR products, along with a negative control (DNA omitted and sterile double-distilled water used instead) were run on a $10 \%$ nondenaturing polyacrylamide gels to assess for the presence of product and any contamination.

\section{Sequencing}

Sequencing was performed commercially from both strands of the DNA (MWG-Biotech, Milton Keynes, Bucks, UK). Briefly, this involves reamplification of the product using nested primers, followed by M13 sub-cloning. Detection was by a Li-Cor infrared detection system. When a mutation was detected, the PCR and the sequencing were both repeated to confirm the result.

\section{Statisticss}

A $P$-value of $<0.05$ was considered to be statistically significant and $\chi^{2}$ analysis was used. 


\section{RESULTS}

\section{p53 IHC}

In total, $70.4 \%$ (19 out of 27) of SCCs demonstrated overexpression of p53 ( $>10 \%$ nuclear staining). Squamous cell carcinoma of the vulva showed different patterns of staining depending on the grade of the tumour with well-differentiated tumours demonstrating expression around the periphery of the keratin pearls and moderately to poorly differentiated SCCs demonstrating expression throughout the tumour (Figure 2). Results are summarised in Table 2.

None of the normal epidermis adjacent to SCC demonstrated overexpression of p53. In all, $40 \%$ (six out of 15) of the LS lesions did demonstrate overexpression of the p53 protein, and staining was confined to the basal/parabasal layers of LS. In all $22.2 \%$ (two out of nine) of adjacent $\mathrm{SH}$ areas were identified as overexpressing p53 with staining identified throughout the epidermis.

There was no statistically significant difference demonstrated between any of the lesions when using $\chi^{2}$ analysis.

\section{TP53 mutations}

In total, $77.8 \%$ (21 out of 27 ) of SCCs demonstrated a TP53 mutation (in codons 136, 213, 214, 234, 235, 248); two SCCs demonstrated mutations and polymorphisms (exons 244 and 258) with 19 SCCs demonstrating the same mutation in exon 5 (codon 136:CAA $\rightarrow$ TAA, Gln $\rightarrow$ stop; Figure 3) and a further SCC demonstrating a mutation in the intron between exons 7 and 8 . In all, $46.7 \%$ (seven out of 15) of adjacent LS lesions were identified as containing a mutation in the TP53 gene with all identified as having the mutation in codon 136; however, one LS lesion had the mutation in codon 136 with a further mutation in exon 7 (codon 248:CGG $\rightarrow$ CAG; $A r g \rightarrow G l n$ ). In all, $22.2 \%$ (two out of 9) of adjacent $\mathrm{SH}$ were identified as having a mutation in the TP53 gene with all (mutant positives) identified as having the mutation in codon 136 and one SH lesion identified as having the mutation in codon 136 plus a mutation in exon 7 , codon 248

\section{Clonality analysis}

Eight cases were identified where the same mutation was identified in the SCC and the adjacent lesion (with a further adjacent lesion demonstrating the same polymorphism as the SCC) resulting in $50 \%$ (eight out of 16 ) of our SCCs having an adjacent lesion with the same clone of cells. When studying

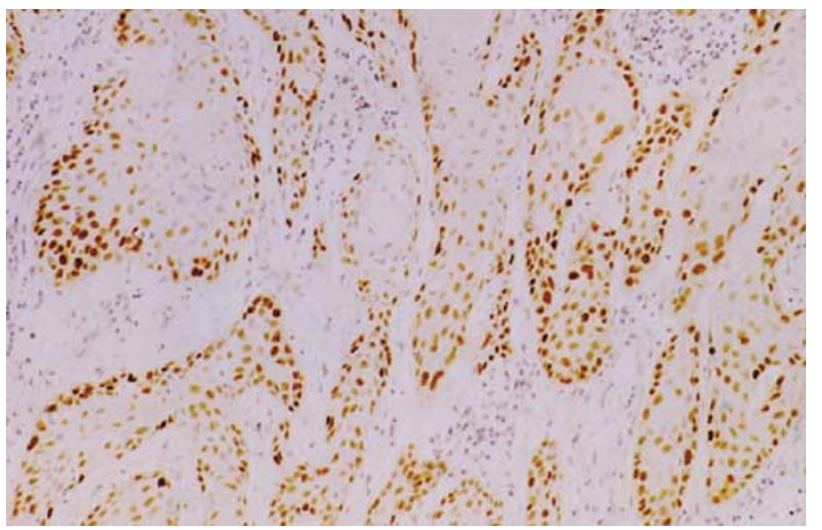

Figure 2 Overexpression of p53 in a well-differentiated SCC: magnification $\times 40$.
Table 2 Results of immunohistochemistry and mutational analysis

\begin{tabular}{|c|c|c|c|}
\hline & Lesion & Immunohistochemistry & Mutation \\
\hline \multirow[t]{3}{*}{ । } & SCC & + & Exon 5 codon 136 \\
\hline & $\mathrm{SH}$ & + & Exon 5 codon 136 \\
\hline & LS & + & Exon 5 codon 136 \\
\hline \multirow[t]{2}{*}{2} & SCC & + & Exon 5 codon 136 \\
\hline & $\mathrm{N}$ & - & Wild type \\
\hline 3 & SCC & - & Exons $5 \& 7$, codons 136 and 244 \\
\hline \multirow[t]{2}{*}{4} & SCC & + & Exon 5 , codon 136 \\
\hline & $\mathrm{N}$ & - & Wild type \\
\hline \multirow[t]{2}{*}{5} & SCC & + & Exon 5, codon 136 \\
\hline & $\mathrm{SH}$ & - & Wild type \\
\hline \multirow[t]{2}{*}{6} & SCC & - & Wild type \\
\hline & $\mathrm{SH}$ & - & Wild type \\
\hline 7 & SCC & + & Wild type \\
\hline \multirow[t]{4}{*}{8} & SCC & + & Exon 5, codon 136 \\
\hline & LS & - & Exon 5, codon 136 \\
\hline & $\mathrm{SH}$ & - & Wild type \\
\hline & $\mathrm{LS}^{\mathrm{a}}$ & - & Wild type \\
\hline 9 & SCC & - & Exon 5, codon 136 \\
\hline \multirow{2}{*}{10} & SCC & + & Exon 5, codon 136 \\
\hline & LS & - & Exon 5, codon 136 \\
\hline \multirow[t]{3}{*}{ |1 } & SCC & - & Exon 5 , codon 136 \\
\hline & $\mathrm{SH}$ & - & Wild type \\
\hline & LS & - & Exon 5, codon 136 \\
\hline \multirow[t]{2}{*}{12} & SCC & + & Exon 5, codon 136 \\
\hline & $\mathrm{SH}$ & - & Wild type \\
\hline \multirow[t]{2}{*}{13} & SCC & + & Exon $5 \& 7$, codons $136 \& 248$ \\
\hline & LS & + & Exon $5 \& 7$, codons $136 \& 248$ \\
\hline \multirow[t]{2}{*}{14} & SCC & + & Wild type \\
\hline & LS & + & Wild type \\
\hline \multirow[t]{2}{*}{15} & SCC & + & Exon 6, codon 213 \\
\hline & LS & - & Wild type \\
\hline 16 & SCC & + & Exon 7, Intron between 7 \& 8 \\
\hline \multirow[t]{2}{*}{17} & SCC & - & Exon 5, codon 136 \\
\hline & $\mathrm{SH}$ & - & Exon $5 \& 7$, codons $136 \& 248$ \\
\hline \multirow[t]{2}{*}{18} & SCC & + & Exon 5 , codon 136 \\
\hline & LS & - & Wild type \\
\hline \multirow[t]{2}{*}{19} & SCC & - & Exon $5 \& 7$, codon $136 \& 258$ \\
\hline & $\mathrm{SH}$ & - & Exon 7, codon 258 \\
\hline \multirow[t]{2}{*}{20} & SCC & - & Exon $5 \& 7$, codon $136 \& 235$ \\
\hline & LS & - & Exon 5 , codon 136 \\
\hline 21 & $\mathrm{SCC}$ & + & Exon $5 \& 7$, codons $136 \& 234$ \\
\hline \multirow[t]{2}{*}{22} & SCC & - & Exon 6, codon 214 \\
\hline & LS & - & Wild type \\
\hline \multirow[t]{2}{*}{23} & SCC & + & Exon 5, codon 136 \\
\hline & LS & + & Exon 5, codon 136 \\
\hline 24 & SCC & + & Wild type \\
\hline 25 & SCC & + & Exon $5 \& 7$, codon $136 \& 248$ \\
\hline 26 & SCC & + & Exon 5, codon 136 \\
\hline 27 & $\mathrm{LS}^{\mathrm{b}}$ & - & Wild type \\
\hline & $L S^{b}$ & + & Wild type \\
\hline & $\mathrm{SCC}$ & + & Wild type \\
\hline & LS & + & Wild type \\
\hline & $\mathrm{SH}$ & + & Wild type \\
\hline
\end{tabular}

$\mathrm{SCC}=$ squamous cell carcinoma of the vulva; $\mathrm{LS}=$ lichen sclerosus; $\mathrm{SH}=$ squamous hyperplasia. 'Lesion not adjacent to SCC. 'Lesions taken at different time.

individual lesions, $46.7 \%$ (seven out of 15 ) of adjacent LS lesions and $33.3 \%$ of adjacent SH showed the same clone of cells as the adjacent SCC.

\section{Correlation between mutation and IHC}

In all, 66.7\% (14 out of 21) of SCC, which overexpressed p53, demonstrated a mutation, though p53 overexpression was also identified in SCCs that showed wild-type TP53 (83.3\%). Adjacent lesions showed correlation with wild-type TP53 and no overexpression of p53 (Table 3). 


\begin{tabular}{|cccc}
\hline 160 & 170 & 180 & 190 \\
\hline CAGGTCITGGCCAGITRGCAAAACATCITGTTGAGGGCA \\
\hline
\end{tabular}

Figure 3 The TP53 sequence for part of the reverse strand of exon 5. The $R$ demonstrates a heterozygous mutation in codon 136 . This sequence was produced from LS adjacent to SCC. The green peak indicates an A, which in wt TP53 is a G (small red peak). This sequence was confirmed by analysis of the forward strand and repeat PCR and sequencing.

Table 3 Correlation of immunohistochemistry and mutations in each lesion

\begin{tabular}{lcccc}
\hline Lesion & IHC+/mt+ & IHC-/mt+ & IHC+/mt- & IHC- $/ \mathbf{m t}-$ \\
\hline SCC & $66.7 \%(|4 / 2|)$ & $33.3 \%(7 / 2 \mid)$ & $83 \%(5 / 6) *$ & $16.7 \%(1 / 6)$ \\
SH & $50 \%(1 / 2)$ & $50 \%(1 / 2) * *$ & $14.3 \%(1 / 7)$ & $85.7 \%(6 / 7)$ \\
LS & $42.8 \%(3 / 7)$ & $57 \%(4 / 7)$ & $37.5 \%(3 / 8)$ & $62.5 \%(5 / 8)$ \\
\hline
\end{tabular}

* Mutation in intron considered wild-type TP53. ** Polymorphism considered wildtype TP53. $\quad I H C=$ immounohistochemistry; $m t=$ mutation; $S C C=$ squamous cell carcinoma of the vulva; $\mathrm{SH}=$ squamous hyperplasia; $\mathrm{LS}=$ lichen sclerosus.

\section{DISCUSSION}

\section{Correlation of sequencing and IHC data}

There was a correlation (66.7\%) between TP53 mutations and p53 protein overexpression in SCC, but positive IHC expression did not necessarily imply a mutation with $83 \%$ of SCCs overexpressing p53 having wild-type TP53.

The antibody used, DO-7, is known to attach to the amino terminus of the human p53 protein at amino-acid location 21-25 (Vojtesek et al, 1992; Stephen et al, 1995) and is able to detect the overexpression of both wild-type and mutant p53. The antibody detects a stabilised form of the protein that, if not stabilised through mutation, is stabilised through other means, which results in an interruption of the degradative pathway of wild-type p53 (Wynford-Thomas, 1992).

\section{TP53 mutations in SCC}

In total, $77.8 \%$ of the SCCs in this study showed a mutation in the TP53 gene. It is possible that those SCCs where no TP53 mutation was identified could have mutations outside exons 5-8 of the TP53 gene, though it has been estimated that less than $5 \%$ of mutations occur outside this highly conserved area.

This work has demonstrated a higher percentage of SCCs with a TP53 mutation compared with that found by other authors, who have shown a range of $32-58 \%$ (Kim et al, 1996; Sliutz et al, 1997; Ngan et al, 1999). There are two possible reasons for this difference: (i) patient details; the majority in this group were older than the other studies and the majority were associated with NNEDV; and (ii) technical differences with this study using direct sequencing and microdissection.

\section{TP53 mutation profile in SCC}

The mutation profile in the TP53 gene can indicate the potential cause of the mutation. Three codons $(213,244$ and 248) from this work were from $\mathrm{CpG}$ sites and other authors have shown that such CpG sites are important regions for mutation in SCC (MildeLangosch et al, 1995; Pilotti et al, 1995; Kim et al, 1996; Ngan et al, 1999). Transitions at CpG sites are believed to be caused by endogenous processes. There are many endogenous processes that could result in carcinogenesis, and these have in part been attributed to cell proliferation (Ames and Gold, 1990). Tissue regeneration after toxicity could increase the frequency of mutation from replication errors. Other processes, such as inflammation, oxygen radical damage accompanying tissue injury, and a flux of macrophages may contribute to the mutation frequency (Harris et al, 1978).

It is possible that the profound itching and resultant scratching associated with NNEDV may contribute to the pathogenesis of associated SCC. It has previously been demonstrated that there is increased cell proliferation in LS and LS adjacent to SCC (Rolfe et al, 2001, 2002) and there may therefore be an increased likelihood of a spontaneous mutation (Hietanen et al, 1995). Inflammatory processes may also be involved in oxidative damage caused by free radicals (Carlson et al, 1998). The inflammatory infiltrate of LS has been shown to possess in excess of $10 \%$ of macrophages (Tsang and Chan, 1992; Carlson et al, 2000), which, if activated, are capable of producing free radicals that have been shown to have a mutagenic activity (Weitzman and Stossel, 1981; Weitberg et al, 1983).

The mutation at codon 136 was demonstrated in half of all lesions studied, and results in a CAA $\rightarrow$ TAA, that is, amino-acid change gln $\rightarrow$ stop. Up to 1996, there had been 10 reports of this mutation in sporadic tumours (Hollstein et al, 1996), including squamous cell carcinoma of the head and neck (Chung et al, 1993), actinic keratosis (Ziegler et al, 1994) and other cancers, for example, oesophageal carcinomas (Huang et al, 1993).

\section{TP53 mutations in adjacent lesions}

Alterations in the p53 pathway are generally regarded as occurring prior to invasion of the basement membrane in tumours of the lung, oesophagus, head and neck, breast and cervix, and as a late event (i.e. after invasion has occurred) in ovarian cancer. In ulcerative colitis and other inflammatory conditions, TP53 mutations have been found in the earliest recognised dysplastic lesions (Burmer et al, 1991, 1992; Yin et al, 1993). This current work on SCC has indicated that TP53 mutations do appear to be early events with eight patients showing an identical TP53 genotype in the adjacent lesion as in the SCC. The relatively low percentage of mutations in $\mathrm{SH}(22 \%)$ could be due to more contaminating cells being present, for example, inflammatory cells in the thickened epidermis, even with the use of microdissection. Ren et al (1996) described the epidermis as being composed of epidermal proliferative units each derived from a single stem cell. It is these stem cells that probably harbour the mutations, which are then passed on to the daughter cells. It has been previously proposed that the stepwise progression of replacement of normal squamous epidermis by atypical keratinocytes does not occur in SCC associated with NNEDV; rather the atypical features are confined to the basal and parabasal layers. Hence, SCC arising from LS may arise directly from basal keratinocytes, which invade the underlying dermis (Carlson et al, 1998).

\section{Clonality in SCC}

In total, $50 \%$ of patients were identified as showing identical mutations in the SCC and adjacent lesion. Only one other study has identified mutations in LS adjacent to SCC and this was in only one case (Milde-Langosch et al, 1995). In our work, $46.7 \%$ of adjacent LS and $33.3 \%$ of $\mathrm{SH}$ adjacent to 
SCC showed identical mutations to the adjacent SCC. Our data suggest that TP53 mutations develop in NNEDV and are intrinsic to the clonal evolution that leads to SCC, as the multiplicity of TP53 mutational events indicate that identical mutations are unlikely to occur independently (Greenblatt et al, 1994).

TP53 mutations appear to play an important role in the pathogenesis of NNEDV to SCC, and those mutations appear to occur through endogenous processes and NNEDV appear to be clonal in origin when comparing TP53 mutational analysis.

\section{ACKNOWLEDGEMENT}

A Williams Trust Scholarship, University of London, supported KJ Rolfe.

\section{REFERENCES}

Ames BN, Gold LS (1990) Chemical carcinogenesis: too many rodent carcinogens. Proc Natl Acad Sci USA 87: 7772

Burmer GC, Crispin DA, Kolli VR, Haggitt RC, Kulander BG, Rubin CE, Rabinovitch PS (1991) Frequent loss of a p53 allele in carcinomas and their precursor in ulcerative colitis. Cancer Commun 3: 167-172

Burmer GC, Rabinovitch PS, Haggitt RC, Crispin DA, Brentnall TA, Kolli VR, Stevens AC, Rubin CE (1992) Neoplastic progression in ulcerative colitis: histology, DNA content, and loss of p53 allele. Gastroenterology 103: $1602-1610$

Carlson JA, Ambros R, Malfetano J, Ross J, Grabowski R, Lamb P, Figge H, Mihn Jr MC (1998) Vulvar lichen sclerosus and squamous cell carcinoma: a cohort, case control, and investigational study with historical perspective: implications for chronic inflammation and sclerosis in the development of neoplasia. Hum Pathol 29: 932- 948

Carlson JA, Grabowski R, Paunovich E, Chichester P, Paunovich E, Malfetano J (2000) Comparative immunophenotypic study of lichen sclerosus: epidermotrophic CD57+ lymphocytes are numerous implications for pathogenesis. Am J Dermatopathol 22: 7-16

Chung KY, Mukhopadhyay T, Kim J, Casson A, Ro JY, Goepfert H, Hong WK, Roth JA (1993) Discordant p53 gene mutations in primary head and neck cancers and corresponding second primary cancers of the upper aerodigestive tract. Cancer Res 53: $1676-1683$

Greenblatt MS, Bennett WP, Hollstein M, Harris CC (1994) Mutations in the p53 tumor suppressor gene: clues to cancer etiology and molecular pathogenesis. Cancer Res 54: $4855-4878$

Harris CC, Hsu IC, Stoner GD, Trump BF, Selkirk JK (1978) Human pulmonary alveolar macrophages metabolise benzo (a) pyrene to proximate and ultimate mutagens. Nature 272: 633-634

Hart WR, Norris HJ, Helwig EB (1975) Relation of lichen sclerosus et atrophicus of the vulva to development of carcinoma. Obstet Gynecol 45: $369-377$

Hietanen SH, Kurvinen K, Syrjänen K, Grenman S, Carey T, McClatchey K, Syrjanen S (1995) Mutation of tumor suppressor gene p53 is frequently found in vulvar carcinoma cells. Am J Obstet Gynecol 173: 1477-1482

Hollstein M, Shomer B, Greenblatt M, Soussi T, Hovig E, Montesano R, Harris CC (1996) Somatic point mutations in the p53 gene of human tumors and cell lines: updated compilation. Nucleic Acid Res 24: $141-146$

Huang Y, Meltzer SJ, Yin J, Tong Y, Chang EH, Srivastava S, McDaniel T, Boynton RF, Zou ZQ (1993) Altered messenger RNA and unique mutational profile of p53 and $\mathrm{Rb}$ in human esophageal carcinomas. Cancer Res 53: $1889-1894$

Kim YT, Thomas NF, Kessis TD, Wilkinson EJ, Hendrick L, Cho KR (1996) P53 mutations and clonality in vulvar carcinomas and squamous hyperplasias: evidence suggesting that squamous hyperplasias do not serve as direct precursors of human papillomavirus-negative vulvar carcinomas. Hum Pathol 27: 389-395

Laude TA, Narayanaswamy G, Rajkumar S (1980) Lichen sclerosus et atrophicus in an eleven year old girl. Cutis 26: 78-80

Levine AJ, Momand J, Finlay CA (1991) The p53 tumour suppressor gene. Nature 351: $453-456$

Meffert JJ, Davis BM, Grimwood RE (1995) Lichen sclerosus. J Am Acad Dermatol 32: $393-416$

Milde-Langosch K, Albrecht K, Joram S, Schlechte H, Giessing M, Loning T (1995) Presence and persistence of HPV infection and p53 mutation in cancer of the cervix uteri and vulva. Int J Cancer 63: 639-645
Ngan HYS, Cheung ANY, Liu SS, Yip PS, Tsao SW (1999) Abnormal expression or mutation of TP53 and HPV in vulvar cancer. Eur J Cancer 35: $481-484$

Pilotti S, D’Amato L, Della Torre G, Donghi R, Longoni A, Giarola M, Sampietro G, De Palo G, Pierotti MA, Rilke F (1995) Papillomavirus, p53 alteration, and primary carcinoma of the vulva. Diag Mol Pathol 4: $239-248$

Ren ZP, Hedrum A, Pontén F, Nister M, Ahmadian A, Lundeberg J, Uhlen M, Ponten J (1996) Human epidermal cancer and accompanying precursors have identical p53 mutations different from p53 mutations in adjacent areas of clonally expanded non-neoplastic keratinocytes. Oncogene 12: $765-773$

Rolfe KJ, Crow JC, Reid WMN, Benjamin E, MacLean AB, Perrett CW (2002) The effects of topical steroids on p53 and Ki67 in vulval lichen sclerosus. Br J Dermatol 147: 503-508

Rolfe KJ, Eva KJ, MacLean AB, Crow JC, Perrett CW, Reid WMN (2001) Cell cycle proteins as molecular markers of malignant change in vulvar lichen sclerosus. Int J Gynaecol Cancer 11: 113-118

Rueda GN, Vighi S, Garcia A, Cardinal L, Belardi MG, di Paola G (1994) Epithelial alterations adjacent to invasive squamous carcinoma of the vulva. J Reprod Med 39: 526-530

Scurry J, Navin K, Östörs A (1997) Comparison of histological features of vulvar lichen sclerosus with and without adjacent squamous cell carcinoma. Int J Gynecol Cancer 7: $392-399$

Sliutz G, Schmidt W, Tempfer C, Speiser P, Gitsch G, Eder S, Schneeberger C, Kainz C, Zellinger R (1997) Detection of p53 point mutations in primary human vulvar cancer by PCR and temperature gradient gel electrophoresis. Gynecol Oncol 64: $93-98$

Stephen CW, Helminen P, Lane DP (1995) Characterisation of epitopes on human p53 using phage-displayed peptide libraries: Insights into antibody peptide interactions. J Mol Biol 248: 58-78

Tsang WYW, Chan JKC (1992) KP1 (CD68) staining of granular cell neoplasms: is KP1 a marker for lysozymes rather than histocytic lineage? Histopathology 21: $84-86$

Vilmer C, Cavelier-Balloy B, Nogues C, Trassard M, Le Doussal V (2000) Analysis of alterations adjacent to invasive vulvar carcinoma and their relationship with the associated carcinoma: a study of 67 cases. Eur J Gynecol Oncol 19: 25-31

Vojtesek B, Bartek J, Midgley CA, Lane DP (1992) An immunochemical analysis of the human nuclear phosphoprotein-p53. New monoclonal antibodies and epitope mapping using recombinant p53. J Immunol Methods 151: 237-244

Wallace HJ (1971) Lichen sclerosus et atrophicus. Trans St. John's Hosp Dermatol Soc 57: 9-30

Weitberg AB, Weitzman SA, Destrempes M, Latt SA, Stossel TP (1983) Stimulated human phagocytes produce cytogenetic changes in cultured mammalian cells. $N$ Engl J Med 308: $26-30$

Weitzman SA, Stossel TP (1981) Mutation caused by human phagocytes. Science 212: $546-547$

Wynford-Thomas D (1992) p53 in tumour pathology: can we trust immunocytochemistry? J Pathol 166: 329-330

Yin J, Harpaz N, Tong Y, Huang Y, Laurin J, Greenwald BD, Hontanosas M, Newkirk C, Meltzer SJ (1993) p53 point mutations in dysplastic and cancerous colitis lesions. Gastroenterology 104: 1633-1639

Ziegler A, Jonason AS, Leffell DJ, Simon JA, Sharma HW, Kimmelman J, Remington L, Jacks T, Brash DE (1994) Sunburn and p53 in the onset of skin cancer. Nature 372: $773-776$ 